Editorial

\title{
Nuevos tiempos, Nuevos desafíos
}

\author{
New Time, New Challenges \\ David Figueroa ${ }^{1}$ \\ 1 Editor Jefe, Revista Chilena de Ortopedía y Traumatología, \\ Santiago, Chile
}

Rev Chil Ortop Traumatol 2017;58:1.

Este es el primer volumen de la Revista de la Sociedad Chilena de Ortopedia y Traumatología que se lanza a través de la nueva plataforma Thieme.com, con interesantes artículos originales y casos clínicos que serán leídos en el sistema Open acces, que permite acceso universal sin pago a los distintos artículos de esta revista.

Thieme no es una empresa nueva, por más de 100 años, esta empresa de alto prestigio mundial en la edición de libros, revistas y artículos de alta calidad, se ha preocupado de diseminar el conocimiento científico a través de todo el mundo.

Thieme publica más de 140 revistas médicas y científicas tanto en formato impreso tradicional como en formato electrónico, algunas de las cuales se imprimen en nombre de sociedades profesionales, así como decenas de otros productos en línea.

Esto nos debe motivar, como socios no solo a leer y conocer los artículos que se envían a RCHOT, sino también a ser partícipes y activos colaboradores en el desarrollo de esta Revista.

Desde que tomamos esta Revista a cargo, no hemos fallado en los tiempos, ni en los volúmenes propuestos, le hemos dado la continuidad que necesita y el Comité Editorial ha sido riguroso en la revisión y selección de los mejores trabajos para su publicación. Muchos socios ya han cooperado compartiendo interesantes casos clínicos, temas de revisión, $\mathrm{y}$ artículos originales, y esperamos que el cambio a una plataforma Internacional, de amplia difusión, sea un incentivo más para que los socios envíen sus artículos para publicación.

El cambio lleva detrás un gran desafío, ser los mejores, que nuestros artículos sean leídos por un gran público, aumentar la producción, e internacionalizar la Revista, para que cada día más colaboradores extranjeros quieran también publicar en ella, y finalmente lograr la anhelada indexación. Ese es nuestro Proyecto futuro, que solo lo lograremos con el apoyo de todos.
Address for correspondence David Figueroa, MD, Santiago, Chile

(e-mail: dhfigueroa@gmail.com).
Copyright $\odot 2017$ by Thieme-Revinter Publicações Ltda, Rio de Janeiro, Brazil
License terms

() (1) $\ominus$ (요 